\title{
High Expression and Purification of Amino-Terminal Fragment of Human Amyloid Precursor Protein in Pichia pastoris and Partial Analysis of Its Properties
}

\author{
Wei Li, Xiang Gao, Junle Ren, Ting An, and Yan Liu \\ School of Life Science, Southwest University, Chongqing 400715, China \\ Correspondence should be addressed to Yan Liu; liuyan@swu.edu.cn \\ Received 29 April 2013; Revised 5 July 2013; Accepted 4 September 2013
}

Academic Editor: Chiu-Chung Young

Copyright (c) 2013 Wei Li et al. This is an open access article distributed under the Creative Commons Attribution License, which permits unrestricted use, distribution, and reproduction in any medium, provided the original work is properly cited.

\begin{abstract}
The cleaved amino-terminal fragment of human amyloid precursor protein (N-APP) binds death receptor 6 (DR6) and triggers a caspase-dependent self-destruction process, which was suggested to contribute to Alzheimer's disease. To investigate the N-APPDR6-induced degeneration pathway at the molecular level, obtaining abundant and purified N-APP is fundamental and critical. The recombinant N-APP has been produced in mammalian expression system. However, the cost and yield disadvantages of mammalian expression system make it less ideal for protein mass production. Here, we successfully expressed and purified recombinant Nterminal 18-285 amino acid residues of human amyloid precursor protein from the methylotrophic yeast Pichia pastoris with a high yield of $50 \mathrm{mg} / \mathrm{L}$. Flow cytometry indicated the purified N-APP-induced obvious apoptosis of human neuroblastoma SHEP cells.
\end{abstract}

\section{Introduction}

Alzheimer's disease (AD) is the most prevalent degenerative disease of the central nervous system. The amyloid precursor protein (APP) has been extensively studied because of its association with the pathogenesis of AD [1]. APP is expressed in adult brain and upregulated in damaged axons [2]. Death receptor 6 (DR6, also known as TNFRSF21) is also highly expressed in adult brain. Given their findings, it is reasonable to assume that the APP-death-receptor mechanism might contribute to adult plasticity or to neurodegeneration after injury or in disease. Interestingly, DR6 is upregulated in injured neurons [3], raising the question as to whether overexpressed DR6 in neurons can trigger ligand-independent degeneration, as reported for $\mathrm{p} 75$ neurotrophin receptor (p75NTR) [4]. Given the genetic evidence linking APP and its cleavage to $\mathrm{AD}$, it was proposed that signalling of APP via DR6 (and possibly p75NTR) may in particular contribute to the initiation or progression of $\mathrm{AD}$, either alone or in combination with other proposed APP-dependent mechanisms, such as amyloid $\beta$-peptide $(\mathrm{A} \beta)$ toxicity [5, 6] or effects of the APP intracellular domain [7]. Of note, previous studies showed immunoreactivity for the APP Nterminus associated with Alzheimer's plaques $[8,9]$, the APP-death-receptor mechanism could support a model in which trophic-factor (TF) deprivation triggers the cleavage of surface APP by $\beta$-secretase, releasing the soluble ectodomain of APP (sAPP $\beta$ ), which is further cleaved by an unknown mechanism to release the amino-terminal fragment of human amyloid precursor protein (N-APP). This then binds DR6 to trigger degeneration through caspase 6 in axons and caspase 3 in cell bodies [10].

Thus, further study is required to determine the full implications of the APP-death-receptor mechanism in development, adult physiology, and disease. Nonetheless, the results already tied APP to a new mechanism for neuronal self-destruction in development and suggested that the APP ectodomain, acting via DR6 and caspase 6, contributes to the pathophysiology of $\mathrm{AD}$.

The availability of pure APP isoforms is essential for studying their processing and biological function. Various expression systems have been used to produce biologically active APP isoforms including bacteria (APP695) [11, 12] 
and baculovirus (APP695, -751, and -770) [13, 14]. Recently, APP695, APP751, and the Kunitz-type protease inhibitor (KPI) domain of an APP homolog cloned from human placenta have been expressed in the yeast Saccharomyces cerevisiae [15]. The methylotrophic yeast Pichia pastoris has been used to produce the ectodomains of APP695, APP751, and APP770 $[16,17]$ and the KPI domain of APP [18, 19]. Although recombinant N-APP (1-286) could have been produced in mammalian cell line system, mass production of N-APP is the prerequisite for its wide application it needs high cost. The high efficient production of N-APP, with large quantity and low cost, is in urgent need for both further fundamental investigation and potential application. The $P$. pastoris expression system is being used successfully and extensively for the production of various recombinant heterologous proteins. P. pastoris is also a eukaryote and thereby provides the potential for producing soluble, correctly folded recombinant proteins that have undergone all the co- and post-translational modifications required for functionality. Recently, the genomic sequence of the GS115 strain of $P$. pastoris has been presented [20].

Here, we report that N-APP (18-285) was highly expressed in the methylotrophic yeast $P$. pastoris and establish the purification procedure. It was detected that the apoptosis rate of human neuroblastoma SHEP cells dealt with different concentrations of N-APP, which proved that N-APP had induced apoptosis on SHEP cells. Thus, a recombinant eukaryotic yeast strain expressing N-APP was constructed successfully.

\section{Materials and Methods}

2.1. Materials. Plasmid pCMV-SPORT6, a vector with the APP gene (GenBank Accession No. BC065529) was purchased from Seajet Scientific Inc. (Beijing, China). Escherichia coli Top10F' ${ }^{\prime}$ was maintained by our lab. P. pastoris wild-type strain GS115 and the expression vector pPIC9K plasmid were purchased from Invitrogen Life Technologies (Carlsbad, CA, USA). All chromatographic media (Q Sepharose fast flow, Sephacryl S-200 high resolution gel filtration) and HiTrap desalting column were obtained from GE Healthcare (Piscataway, NJ, USA). Polymerase chain reaction (PCR) products used for cloning were confirmed by sequencing at Invitrogen (Shanghai, China). Protein molecular weight markers were from New England Biolabs (Ipswich, MA, USA). Mouse anti-His monoclonal antibody and secondary antibody horseradish peroxidase- (HRP-) conjugated goat anti-mouse immunoglobulin $\mathrm{G}(\mathrm{IgG})$ used for western was obtained from the Antibody Research Center (Shanghai Institute of Biochemistry and Cellular Biology, Chinese Academy of Sciences) and Santa Cruz Biotechnology (Santa Cruz, CA, USA), respectively. All other chemical reagents were of analytical grade.

2.2. Construction of the Expression Vector. DNA encoding the mature N-terminal lysine (amino acid 18) to the $\alpha$ secretase site of APP285 (amino acid 285) was prepared by PCR using the $5^{\prime}$ forward primer $5^{\prime}$ CCGCTCGAGAAAAGACTGGAGGTACCCACTGATGGTAATG $3^{\prime}$ and the $3^{\prime}$ reverse primer 5'GGAATTCCTTATTAATGATGATGATGATGATGGGATCCTCTTGGAACCAACTCTTCCACAGACTCTGTGGTGGTG3', pCMV-SPORT6 as the template. These oligonucleotides include an Xho I and an EcoR I site for cloning into the Xho I and EcoR I site of the $P$. pastoris expression vector pPIC9K. The $3^{\prime}$ reverse primer contained double stop codon. In order to express the native $\mathrm{N}$-terminus of APP, an Xho I restriction site was introduced to allow in-frame cloning into the $\alpha$-factor secretion signal of pPIC9K expression vector, and a nucleotide sequence encoding the KEX2 cleavage site was placed ahead of N-APP (18-285). At the C-terminus, the stop codon and a nucleotide sequence encoding the thrombin cleavage site were introduced along with an EcoR I restriction site (Table 1). The PCR product was digested with Xho I and EcoR I and cloned into the same sites of pPIC9K. The recombinant plasmid pPIC9K-N-APP (18-285) was transformed into competent E. coli Top $10 F^{\prime}$, and the fragment was validated by restriction enzyme digestion with Xho I and EcoR I and confirmed by DNA sequencing.

\subsection{Transformation of P. pastoris and Selection of Transform-} ants. SacI was used to linearize $5-10 \mu \mathrm{g}$ pPIC9K-N-APP plasmid DNA, and linear DNA was then transformed into the competent $P$. pastoris GS115 cells using a Gene Pulser system (Bio-Rad; conditions used: $1.5 \mathrm{kV}, 200 \Omega, 25 \mu \mathrm{F}$, and $4.5 \mathrm{~ms}$ ). pPIC9K blank plasmid vector alone was also linearized and transformed into P. pastoris GS115 cells as a negative control. After initial selection of histidine utilization plus $\left(\mathrm{His}^{+}\right)$ transformants on regeneration dextrose medium (RDB) plates which did not add histidine, they were spread on yeast extract peptone dextrose medium (YPD)-geneticin plates with $3 \mathrm{mg} / \mathrm{mL}$. All geneticin-resistant colonies were plated in duplicate onto either minimal methanol medium (MM) or minimal dextrose medium (MD) plates to characterize the methanol-utilizing phenotype. The methanol utilization plus $\left(\mathrm{Mut}^{+}\right)$phenotype strains were obtained from MM plates, and the inserts were verified by colony PCR.

\subsection{Expression and Purification of Recombinant Protein in $P$.}

Pastoris. Positive transformants were tested for their ability to secrete N-APP into the cell culture supernatants using the method according to the Invitrogen manual. The high yield strain was inoculated into a flask containing $100 \mathrm{~mL}$ buffered glycerol-complex medium (BMGY). Shaken at $30^{\circ} \mathrm{C}, 250 \mathrm{rpm}$ for $48 \mathrm{~h}$, the culture was centrifuged at $4^{\circ} \mathrm{C}, 3000 \mathrm{~g}$ for $5 \mathrm{~min}$. The collected cells were resuspended in $200 \mathrm{~mL}$ buffered methanol-complex medium (BMMY) and allowed to grow at $30^{\circ} \mathrm{C}$ for $72 \mathrm{~h}$. Methanol was added at the first $24 \mathrm{~h}$ to a final concentration of $1.0 \%$ to maintain induction. The culture was centrifuged at $6000 \mathrm{rpm}$ for $20 \mathrm{~min}$ and then analyzed by sodium dodecyl sulfate polyacrylamide gel electrophoresis (SDS-PAGE). The filtered expressed supernatant was desalted for buffer exchange on HiTrap desalting column; exchanging buffer was lysis buffer ( $20 \mathrm{mM}$ imidazole, $5 \mathrm{mM}$ EDTA, $\mathrm{pH}$ 6.0). The sample was then loaded onto a Q-Sepharose fast flow column (Q-Sepharose FF column, $1.6 \times 25 \mathrm{~cm}$, flow rate $10 \mathrm{~mL} / \mathrm{min}$ ). The column was preequilibrated with buffer 


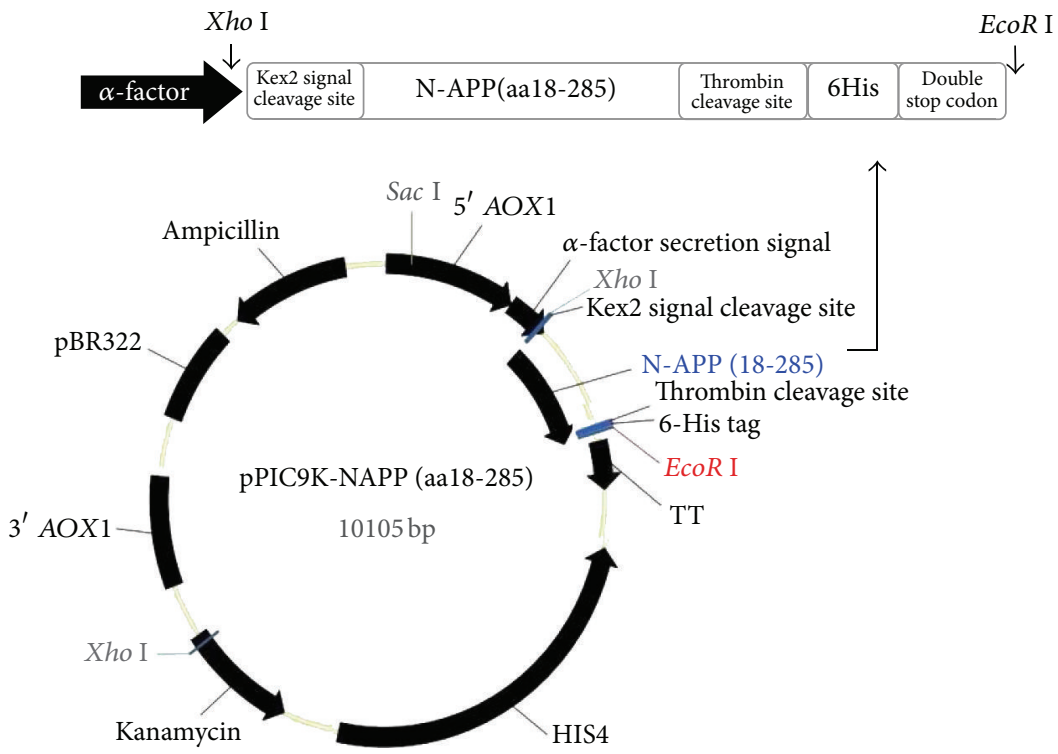

FIGURE 1: Design of recombinant plasmid pPIC9K-N-APP (18-285).

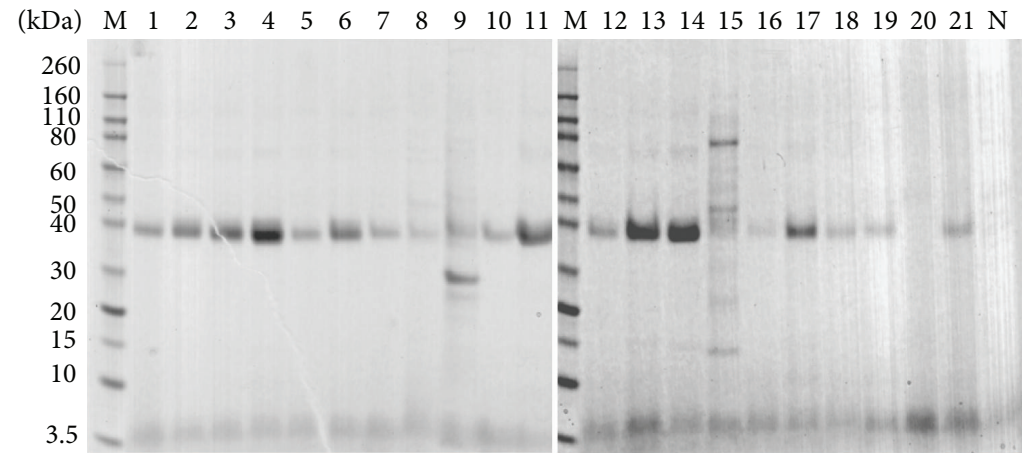

(a)

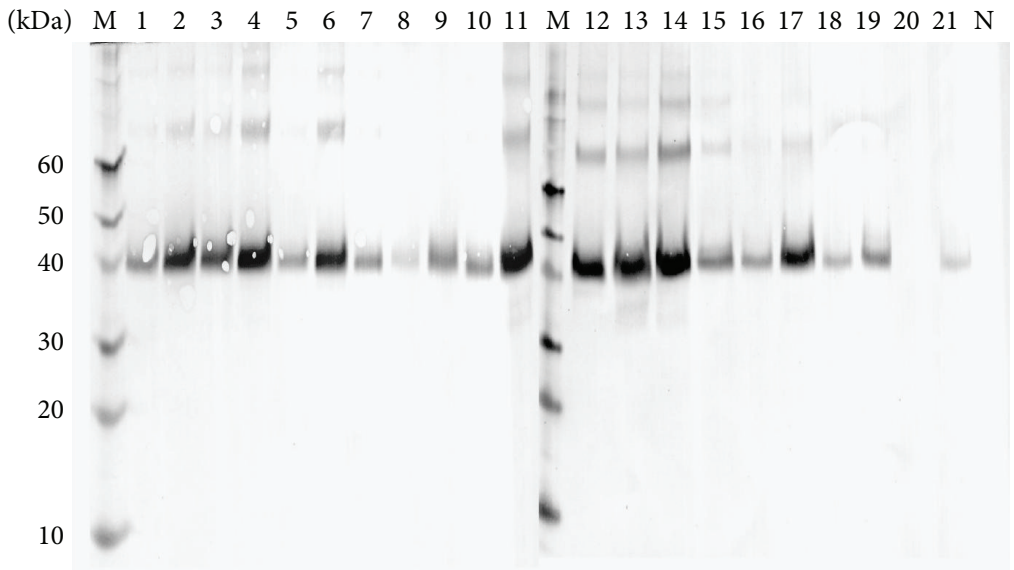

(b)

FIGURE 2: (a) SDS-PAGE screening of high expression recombinant strain. M: molecular weight protein marker; N: negative control GS115/pPIC9K; lanes 1-21: expressed supernatants GS115/pPIC9K-N-APP; (b) Western blot analysis of recombinant proteins. M: prestained protein molecular weight marker; lanes 1-21: expressed supernatants GS115/pPIC9K-N-APP; N: negative control GS151/pPIC9K. 
TABLE 1: Primer sequence used for PCR amplification of N-APP.

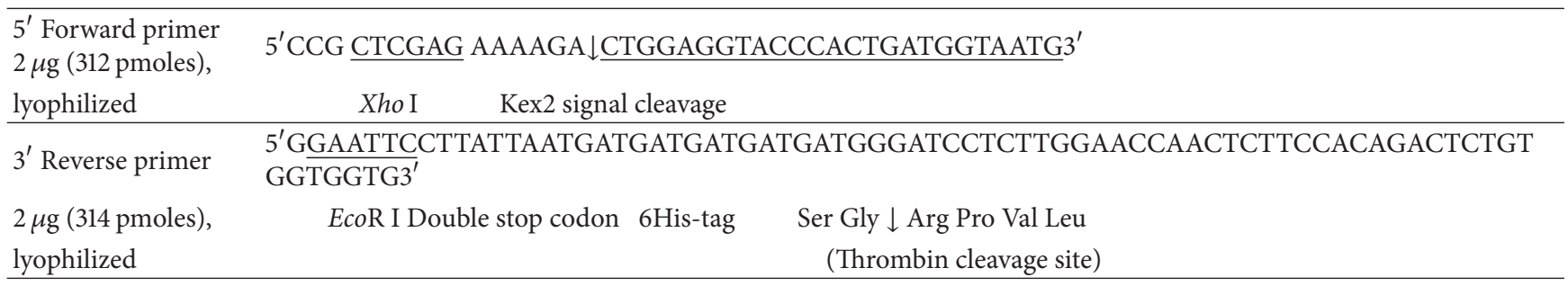

TABLE 2: Summary of N-APP purification.

\begin{tabular}{|c|c|c|c|c|}
\hline Purification step & Total volume $(\mathrm{mL})$ & Total protein $(\mathrm{mg})$ & Purity $(\%)^{\mathrm{a}}$ & Recovery (\%) \\
\hline Culture supernatant & 400 & 204 & 35 & 100 \\
\hline Q-Sepharose FF & 50 & 43.1 & 80 & 25.9 \\
\hline Ultrafiltration & 8 & 30.4 & 87 & 70.5 \\
\hline Sephacryl S-200 & 13.3 & 23.6 & 96 & 77.6 \\
\hline
\end{tabular}

${ }^{a}$ According to densitometric analysis of SDS-PAGE.

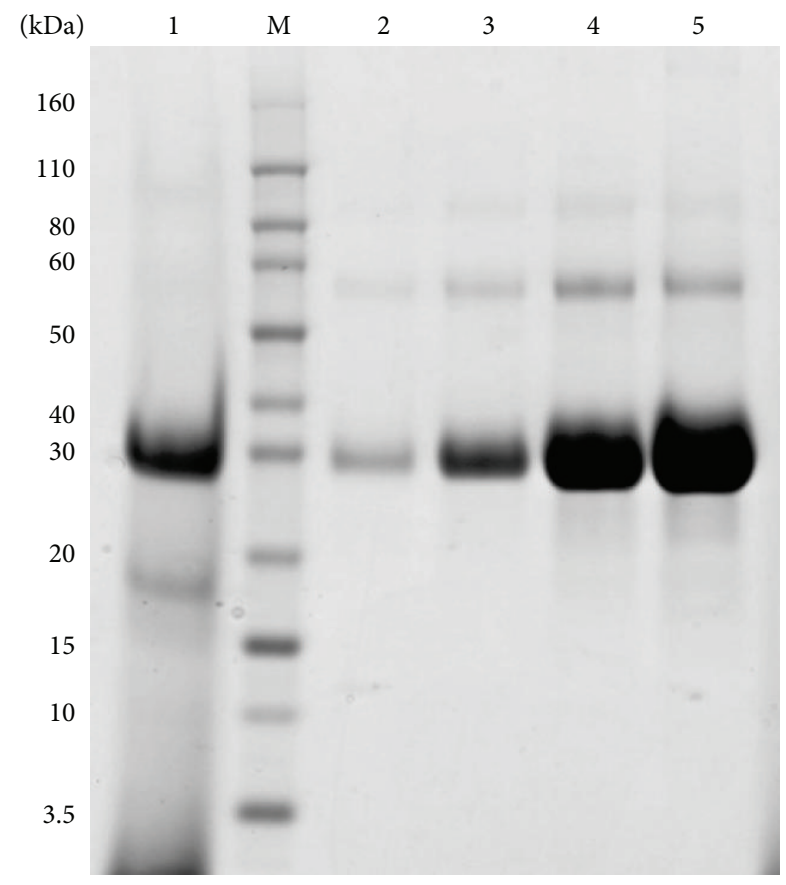

FIGURE 3: Purified recombinant N-APP by Q Sepharose fast flow chromatography. M: protein marker; lane 1: culture supernatant; lanes 2-5: purified N-APP from different tubes after ion exchangers.

A (20 mM imidazole, $50 \mathrm{mM} \mathrm{NaCl}, 5 \mathrm{mM}$ EDTA, pH 6.0) then washed with buffer $\mathrm{A}$ and the bound protein was eluted with buffer B (20 mM Tris- $\mathrm{HCl}, 500 \mathrm{mM} \mathrm{NaCl}, 5 \mathrm{mM}$ EDTA, $\mathrm{pH} 7.4)$, and the eluting proteins were collected $(50 \mathrm{~mL})$. The eluted fractions were concentrated by centrifugal filter devices Amicon Ultra-15 (Millipore), and further purified using Sephacryl S-200 high resolution which was equilibrated and eluted with $20 \mathrm{mM}$ Tris- $\mathrm{HCl}, 150 \mathrm{mM} \mathrm{NaCl}, \mathrm{pH}$ 8.0. The purified protein was analyzed by $12 \%$ SDS-PAGE.
2.5. Gel Electrophoresis and Western Blotting. Samples were separated by SDS-PAGE and electrophoretically transferred onto nitrocellulose (Millipore). Primary antibodies were detected with mouse anti-His monoclonal antibody secondary antibody using HRP-conjugated goat anti-mouse, the specific protein bands were incubated with diaminobenzidine (DAB) kit (Amersham Pharmacia Biotech).

2.6. Stability of the Purified Protein. After being purified by Q-Sepharose FF column, the recombinant proteins were placed at $4^{\circ} \mathrm{C}$ and $20^{\circ} \mathrm{C}$ for $4 \mathrm{~d}$, respectively, then analyzed by SDS-PAGE.

2.7. Effect of Recombinant N-APP on SHEP Cells In Vitro Analyzed by Flow Cytometry. To explore the effect of the human recombinant N-APP protein on neurocyte, we observed the influence of N-APP on the apoptosis of SHEP. The logarithmic phase cells were processed with different concentrations of N-APP protein followed by morphological evaluation.

2.8. Statistical Analysis. Data were analyzed using Excel (version 2007) and represented as mean \pm standard deviation (SD) between replicates. At least two independent experiments were performed for each analysis, and the number of replicates $(n)$ for each experiment is indicated. Statistical significance was evaluated by Student's $t$-test; $P<0.05$ was considered as significant; $P<0.01$ was considered as statistically extremely significant. $P$ values are indicated by asterisks in the graphs $\left({ }^{*} P<0.05 ;{ }^{* *} P<0.01\right)$.

\section{Results}

3.1. Construction and Identification of Recombinant Expression Vector. The Xho I and EcoR I sites were used to insert the DNA fragment encoding the human N-APP (18-285) in the $P$. pastoris expression vector $\mathrm{pPIC9K}$ which contains an $S$. cerevisiae alpha factor leader and an alcohol oxidase 1 (AOX1) 


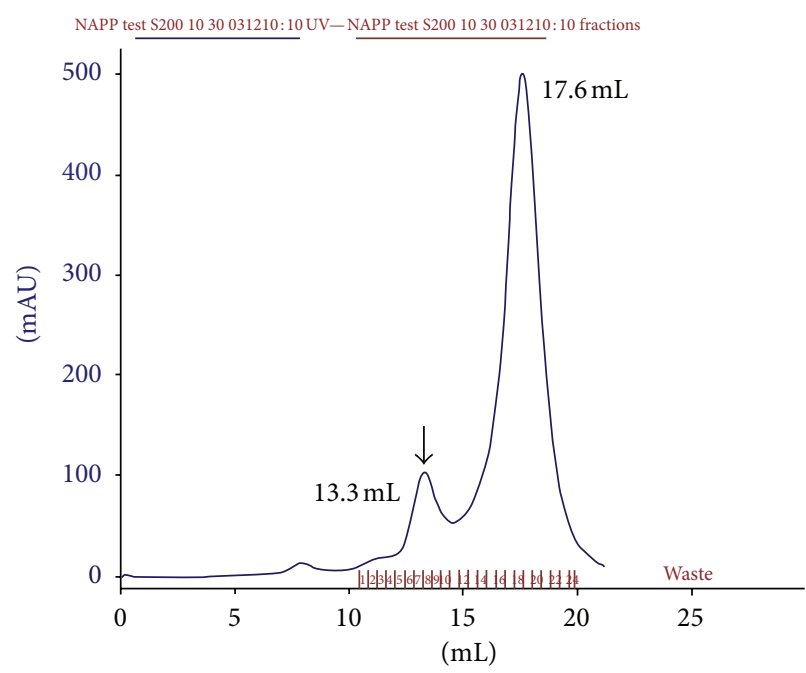

(a)

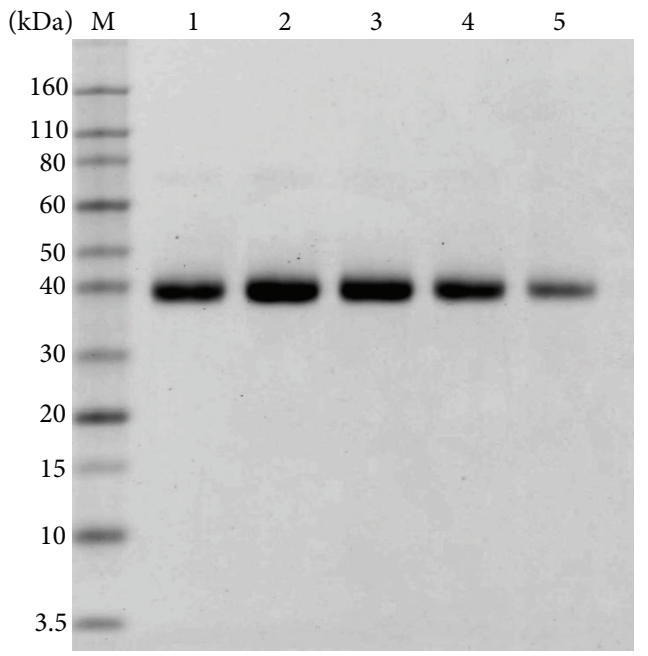

(b)

FIGURE 4: Purified recombinant N-APP by Sephacryl S-200 high resolution chromatography. (a) Profile of gel filtration of the fractions from the Q Sepharose fast flow chromatography. The arrow indicates the purified protein eluting peak ( $13.3 \mathrm{~mL})$ which corresponds to the 6 th, 7 th, 8th, 9th, and 10th collection tube; (b) SDS-PAGE analysis of the purified N-APP after gel filtration. M: protein marker; lanes 6-10: the eluting fraction which corresponds to the 6th, 7th, 8th, 9th, and 10th collection tube.

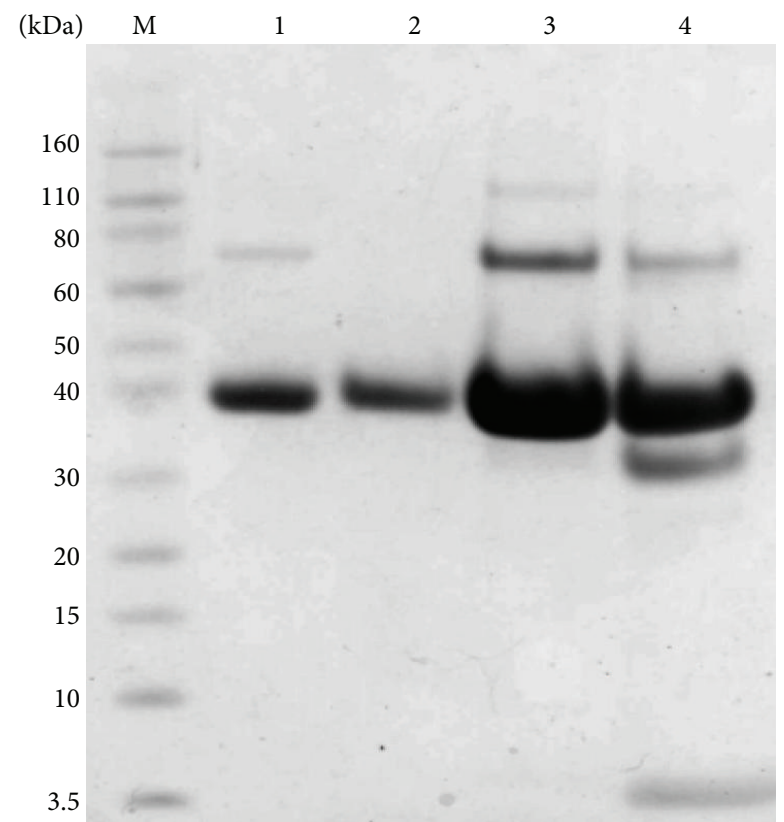

FIGURE 5: SDS-PAGE analysis of stability of the purified protein. M: protein marker; lane 1, 2: purified protein by Q Sepharose fast flow chromatography; lane 3: the purified protein by Q Sepharose fast flow chromatography which was incubated at $4^{\circ} \mathrm{C}$ for $4 \mathrm{~d}$; lane 4 : the purified protein by $\mathrm{Q}$ Sepharose fast flow chromatography which was incubated at $20^{\circ} \mathrm{C}$ for $4 \mathrm{~d}$.

promoter (Figure 1). There was a site-specific recognition sequence of thrombin between 6His-tag and N-APP (18285) gene fragment for the removal of His tag. The constructed structure of the expression vector was confirmed by restriction enzyme digestion and DNA sequencing (data not shown).

3.2. Expression and Western Blotting. The positive colonies were cultured and induced to screen high-expression recombinant strains. SDS-PAGE analysis showed that N-APP (18285) was successfully expressed in the P. pastoris GS115 transformant. The molecular weight of the protein was approximately $38 \mathrm{kDa}$ as determined by SDS-PAGE (Figure 2(a)). Western blotting analysis showed that the protein was recognized specifically by mouse anti-His antibody demonstrating that the expressed heterogeneous protein was recombinant N-APP (18-285) (Figure 2(b)).

3.3. Purification of $N$-APP. The culture supernatant was primarily purified by a Q Sepharose FF column (Figure 3). The fractions containing the target protein were collected and concentrated by centrifugal filter devices. N-APP was further purified with Sephacryl S-200 high resolution column (Figure 4(a)). Following this process, the purity of N-APP was $>95 \%$, as revealed by SDS-PAGE (Figure 4(b)). The purified protein was estimated using the bicinchoninic acid (BCA) assay, and its yield was about $50 \mathrm{mg} / \mathrm{L}$ (Table 2).

3.4. Stability of the Purified Protein. When the recombinant proteins were purified using Q-Sepharose FF column, the bound protein was eluted with buffer B $(20 \mathrm{mM}$ Tris- $\mathrm{HCl}$, $500 \mathrm{M} \mathrm{NaCl}, 5 \mathrm{mM}$ EDTA, pH 7.4). At pH 7.4, the temperatures (at $4^{\circ} \mathrm{C}$ and $20^{\circ} \mathrm{C}$ ) for stability of the recombinant proteins were studied. We put the recombinant proteins under $4^{\circ} \mathrm{C}$ and $20^{\circ} \mathrm{C}$ for $4 \mathrm{~d}$, respectively. SDS-PAGE electrophoretograms of the recombinant proteins showed that the proteins were obviously not degraded (Figure 5). 


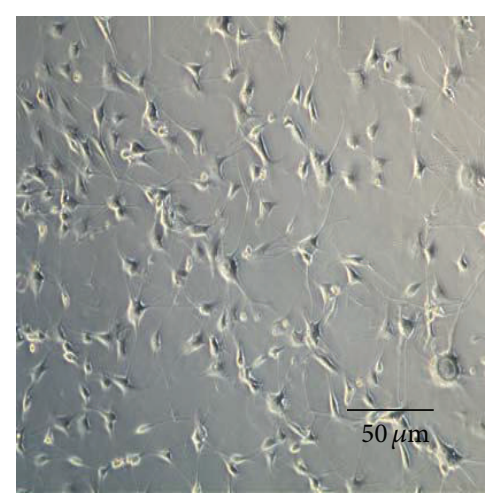

(a)

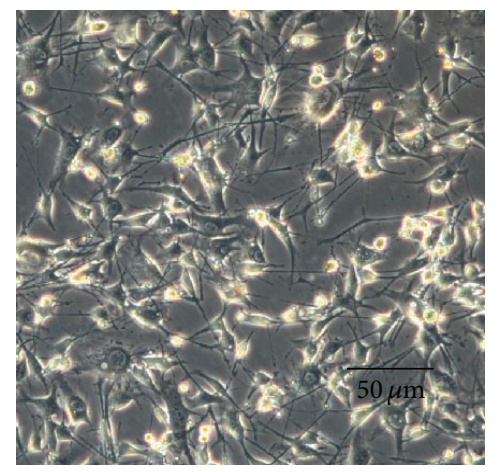

(d)

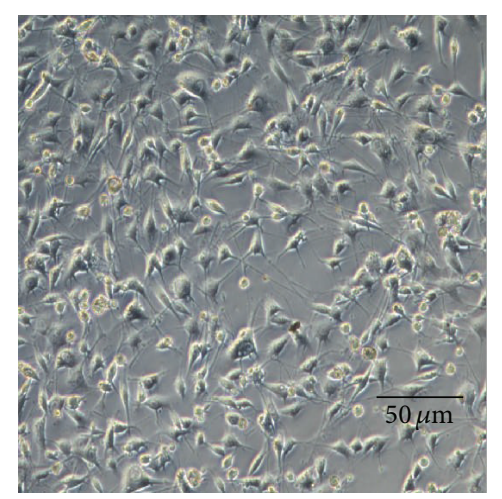

(b)

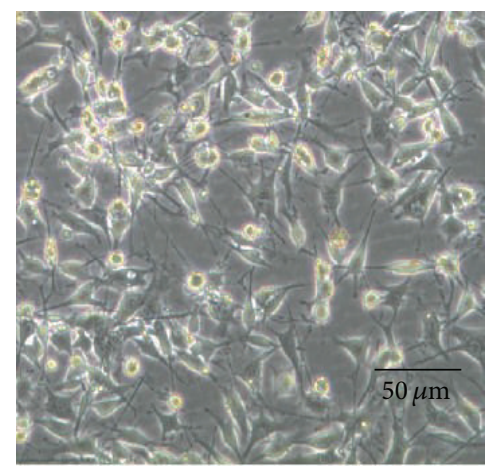

(e)

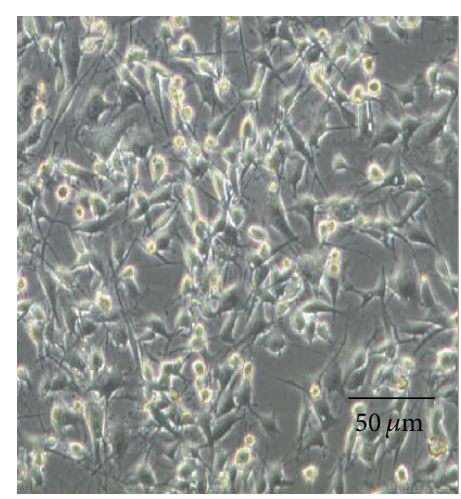

(c)

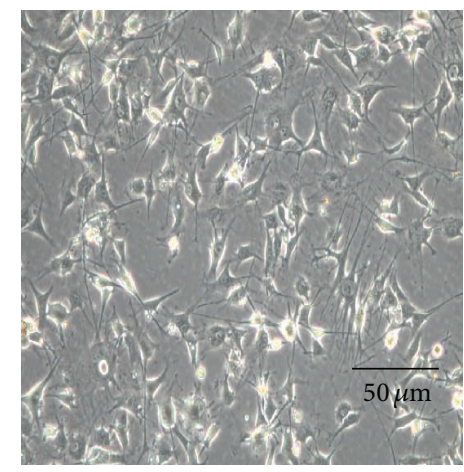

(f)

FIGURE 6: Effect of N-APP on SHEP cells cultured 24h (200x). (a) Control; (b)-(f): N-APP at different concentrations of 2.5, 5, 10, 20, and $40 \mu \mathrm{g} / \mathrm{mL}$.

3.5. Effect of Recombinant N-APP on SHEP Cells In Vitro. Recombinant N-APP changes the morphology of SHEP cells. Proliferating SHEP cells were treated with N-APP at different concentrations of $0,2.5,5,10,20$, and $40 \mu \mathrm{g} / \mathrm{mL}$. Pictures (Figure 6) were taken $24 \mathrm{~h}$ after treatment. In the controls, the cells showed intact cell morphology, whereas N-APP-treated cells appeared rounded and floating and showed membrane blebbing characteristic of apoptotic cells.

Effect of N-APP on SHEP cells was further analyzed by flow cytometry. The Annexin V-fluorescein isothiocyante (FITC) kit uses annexin V conjugated with FITC to label phosphatidylserine sites on the membrane surface. The kit includes propidium iodide (PI) to label the cellular DNA in necrotic cells where the cell membrane has been totally compromised. This combination allows the differentiation among early apoptotic cells (annexin V positive, PI negative), necrotic cells (annexin V positive, PI positive), and viable cells (annexin V negative, PI negative). The results showed that N-APP induced cultured cell's apoptosis. The assay not only gives information about the numbers of vital (AV-/PI-) and apoptotic (AV+/PI-) cells, but also concurrently provides the number of necrotic cells $(\mathrm{AV}+/ \mathrm{PI}+)$ (Figure 7$)$. SHEP cells were cultured for $12-48 \mathrm{~h}$ in the presence of $\mathrm{N}$ APP with different concentrations. The data were presented as mean $\pm \mathrm{SD}$; dealing with different concentrations $(0,2.5,5,10$, 20 , and $40 \mu \mathrm{g} / \mathrm{mL})$ for $12 \mathrm{~h}$, apoptosis rates were $(1.6 \pm 0.5) \%$, $(1.9 \pm 0.5) \%,(1.9 \pm 0.6) \%,(2.6 \pm 0.5) \%,(3.2 \pm 0.7) \%$, and
$(3.8 \pm 0.8) \%$; for $24 \mathrm{~h}$, apoptosis rates were $(2.5 \pm 0.5) \%$, $(4.9 \pm 0.4) \%,(5.7 \pm 0.5) \%,(6.8 \pm 0.6) \%,(7.6 \pm 0.4) \%$, and $(7.3 \pm 0.8) \%$; For $48 \mathrm{~h}$ apoptosis rates were $(2.8 \pm 0.5) \%$, $(5.5 \pm 0.4) \%,(6.4 \pm 0.1) \%,(8.1 \pm 0.4) \%,(9.5 \pm 0.5) \%$, and $(8.9 \pm 0.6) \%$ (Figure 8$)$. The results showed that the apoptosis rate of the experimental groups was significantly higher than that of the control groups. The cell apoptosis rate was raised with the extension of time. Overall cell apoptosis rate was in upward trend with the increasing concentration of N-APP and only at $40 \mu \mathrm{g} / \mathrm{mL}$ (cultured for $24-48 \mathrm{~h}$ ) fell slightly.

\section{Discussion}

Nikolaev et al. [10] reported APP and DR6 activated a caspase-dependent apoptosis program. Their research revealed a new mechanism. APP was cut by a not yet known secretase to yield N-APP in trophic-factor deprivation. The N-APP bound DR6, triggering degeneration of both neuronal cell bodies and axons depend on caspase- 3 and caspase- 6 , respectively. The work also identified a new $\mathrm{AD}$ target and proved that the neurodegeneration seen in $\mathrm{AD}$ was not only the consequence of accumulate $\mathrm{A} \beta$ alone, but a combination of some ignored portions of APP contributing to AD.

In our study, the cDNA encoding N-APP (18-285) with one His-tag and one thrombin-cleavage site was cloned in the P. pastoris expression plasmid pPIC9K. His-tag will make the 


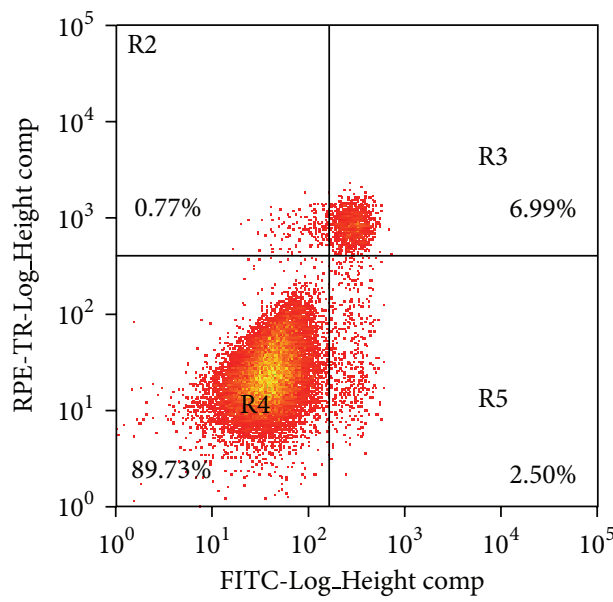

(a) Control

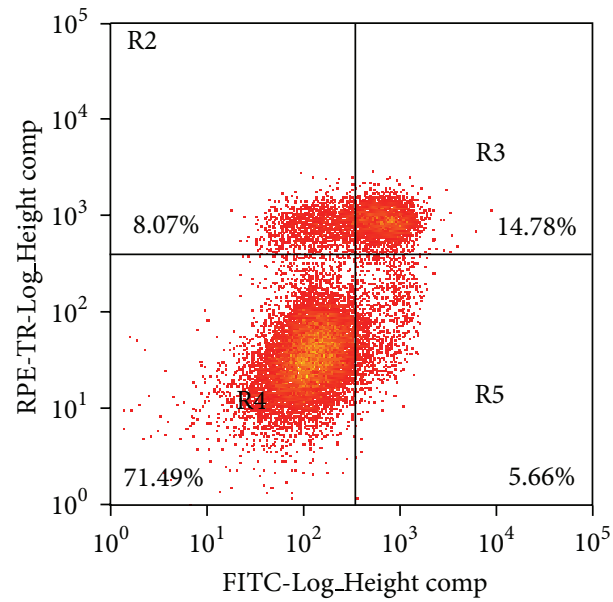

(c) $5.0 \mu \mathrm{g} / \mathrm{mL}$

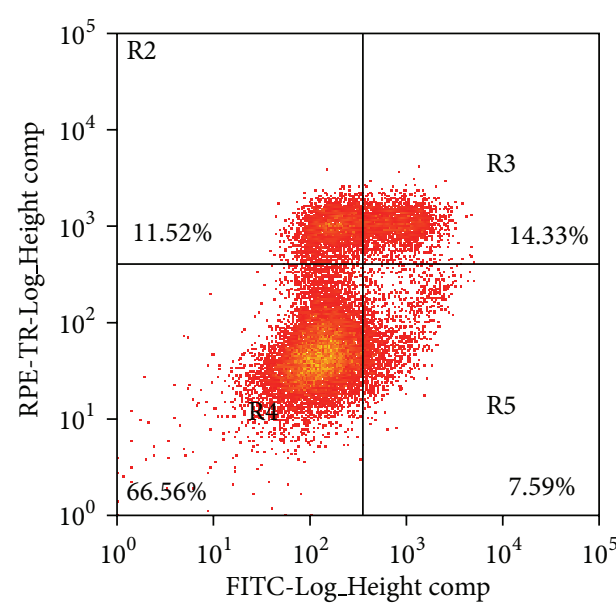

(e) $20 \mu \mathrm{g} / \mathrm{mL}$

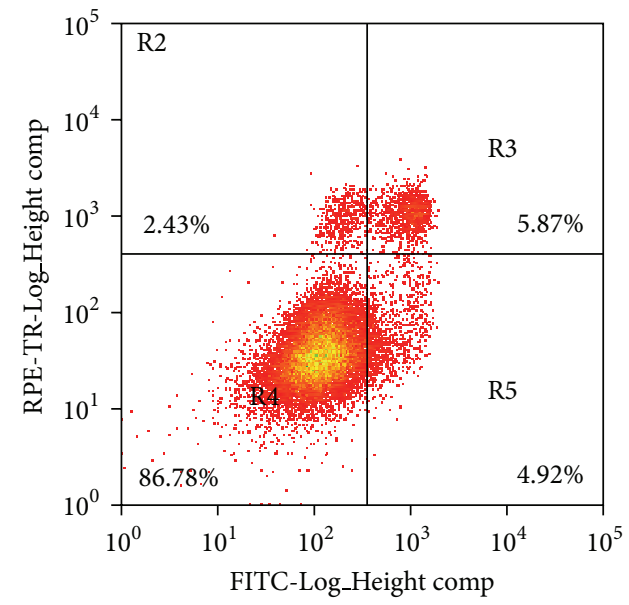

(b) $2.5 \mu \mathrm{g} / \mathrm{mL}$

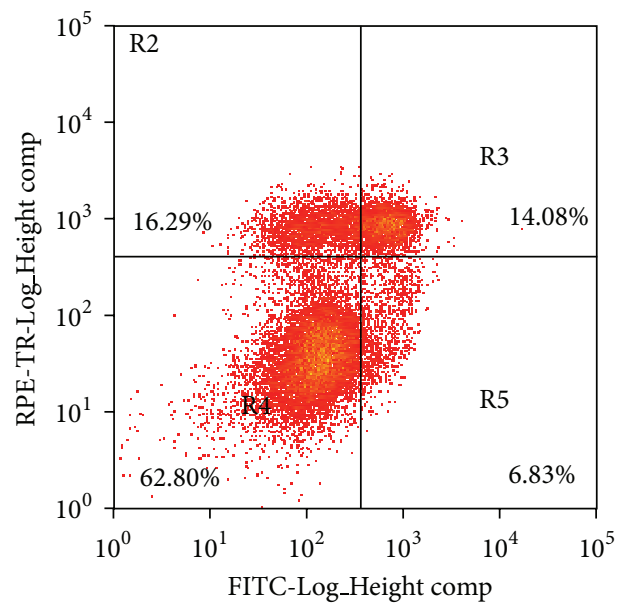

(d) $10 \mu \mathrm{g} / \mathrm{mL}$

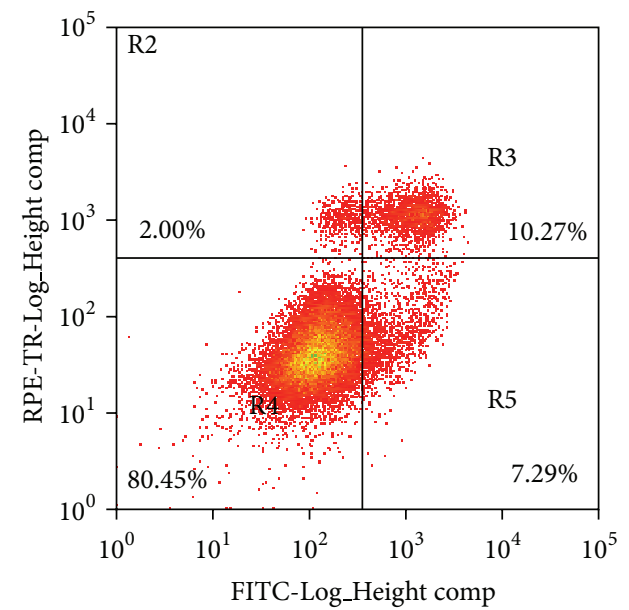

(f) $40 \mu \mathrm{g} / \mathrm{mL}$

FIGURE 7: Apoptosis of SHEP cells cultured $24 \mathrm{~h}$ in different concentrations of N-APP. (a): Control; (b)-(f): N-APP at different concentrations of $2.5,5,10,20$, and $40 \mu \mathrm{g} / \mathrm{mL}$; for $24 \mathrm{~h}$, apoptosis rates were $4.9 \%, 5.7 \%, 6.8 \%, 7.6 \%$, and $7.3 \%$. 


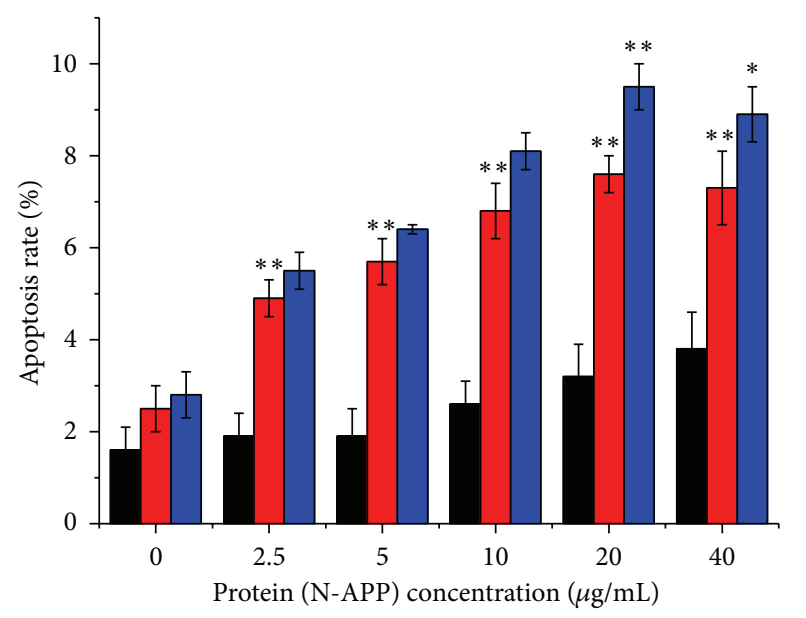

$$
\begin{aligned}
& \square 12 \mathrm{~h} \\
& \square 24 \mathrm{~h} \\
& \square 48 \mathrm{~h}
\end{aligned}
$$

FIGURE 8: Effect of different concentrations of N-APP on SHEP cells apoptosis with the extension of time. ${ }^{*} P<0.05 .{ }^{* *} P<$ 0.01 , compared with control group without N-APP. The data were presented as mean $\pm \mathrm{SD}$, dealing with different concentrations $(0$, $2.5,5,10,20,40 \mu \mathrm{g} / \mathrm{mL})$ for $12 \mathrm{~h}$, apoptosis rates were $(1.6 \pm 0.5) \%$, $(1.9 \pm 0.5) \%,(1.9 \pm 0.6) \%,(2.6 \pm 0.5) \%$, and $(3.2 \pm 0.7) \%$, and $(3.8 \pm 0.8) \%$; for $24 \mathrm{~h}$, apoptosis rates were $(2.5 \pm 0.5) \%,(4.9 \pm 0.4) \%$, $(5.7 \pm 0.5) \%$, $(6.8 \pm 0.6) \%,(7.6 \pm 0.4) \%$, and $(7.3 \pm 0.8) \%$; For $48 \mathrm{~h}$ apoptosis rates were $(2.8 \pm 0.5) \%,(5.5 \pm 0.4) \%,(6.4 \pm 0.1) \%$, $(8.1 \pm 0.4) \%,(9.5 \pm 0.5) \%$, and $(8.9 \pm 0.6) \%$.

purification procedure easy by $\mathrm{Ni}+$ affinity chromatography; thrombin-cleavage site can cut the His-tag after purification. However, we found it a little difficult for the recombinant protein to bind $\mathrm{Ni}+$ column. Finally, ion exchange chromatography and gel filtration chromatography were used to purify the recombinant protein. Optimum conditions leading to maximum recombinant-protein yield: recombinant strain was cultured in $100 \mathrm{~mL}$ BMGY medium $48 \mathrm{~h}$ to make full use of the glycerol to get the high density of the cells, then the cell pellets were harvested and resuspended in large volume $200 \mathrm{~mL}$ BMMY medium, added $100 \%$ methanol to a final concentration of $1 \%(\mathrm{v} / \mathrm{v})$ at first $24 \mathrm{~h}$, and induction time of $72 \mathrm{~h}$. After purification, the purified protein was very stable with an estimated yield of $50 \mathrm{mg} / \mathrm{L}$. We proved that recombinant N-APP (18-285) induced apoptosis of SHEP cells. The availability of large amounts of high stability purified recombinant proteins could facilitate further studies on its biological activities. Previous studies showed that a cleaved amino-terminal fragment of N-APP could bind DR6 to trigger neuron death via a widespread caspase-dependent self-destruction program, and it was found that DR6 induces apoptosis when it is overexpressed. Data strongly demonstrated that DR6-induced apoptosis is caspase dependent. On the other hand, DR6-induced apoptosis involves cytochrome c release and Bax translocation. DR6 induced apoptosis through a pathway that exclusively depends on the mitochondrial pathway and possibly through interacting with Bax. A conclusion could be drawn that DR6 induces apoptosis of
SHEP cells via an intrinsic bax-mitochondrion-cytochrome c-caspase protease pathway. Here, firstly, DR6 could be expressed by SHEP cells as nerve cells, and DR6 is activated locally by N-APP, which triggers neuronal cell body apoptosis because DR6 signals via BAX and caspase 3 in cell bodies. Secondly, the apoptotic rate of SHEP cells as cancer cells is different from normal neuronal cell DR6 is broadly expressed by developing neurons and is required for normal cell body death both in vivo and after trophic-factor deprivation in vitro [10], but DR6 may be lower expressed in SHEP cells than that of other neurons. So, number of apoptotic cells was found to be very low, even $48 \mathrm{~h}$ after addition of high concentration of N-APP, but the cell apoptosis rate was rising with the extension of time. Overall cell apoptosis rate was upward trend with the increasing concentration of N-APP, and only at $40 \mu \mathrm{g} / \mathrm{mL}$ (cultured for 24-48 h) fell slightly. This study was designed to get N-APP in P. pastoris and evaluate whether the N-APP could induce apoptosis of SHEP cells. Indeed, its possible mechanisms of N-APP-induced apoptosis in SHEP cells needed to be further studied.

In conclusion, the work described here provided a feasible method to express high yield recombinant amino-terminal fragment of APP in the methylotrophic yeast P. pastoris and established the purification procedure. It would provide a foundation for the further structural and functional characterization of N-APP associated with AD.

\section{Acknowledgment}

The authors thank Ya Ha and members of his laboratory (Department of Pharmacology, School of Medicine, Yale University) for helpful discussions and suggestions. The authors are especially grateful to Chongqing Natural Science Foundation (no. CSTC2011BB0146) for financial support.

\section{References}

[1] J. Kang, H.-G. Lemaire, A. Unterbeck et al., "The precursor of Alzheimer's disease amyloid A4 protein resembles a cell-surface receptor," Nature, vol. 325, no. 6106, pp. 733-736, 1987.

[2] I. M. Medana and M. M. Esiri, "Axonal damage: a key predictor of outcome in human CNS diseases," Brain, vol. 126, no. 3, pp. 515-530, 2003.

[3] L. W. Chiang, J. M. Grenier, L. Ettwiller et al., "An orchestrated gene expression component of neuronal programmed cell death revealed by cDNA array analysis," Proceedings of the National Academy of Sciences of the United States of America, vol. 98, no. 5, pp. 2814-2819, 2001.

[4] N. Plachta, C. Annaheim, S. Bissière et al., "Identification of a lectin causing the degeneration of neuronal processes using engineered embryonic stem cells," Nature Neuroscience, vol. 10, no. 6, pp. 712-719, 2007.

[5] J. Hardy and D. J. Selkoe, "The amyloid hypothesis of Alzheimer's disease: progress and problems on the road to therapeutics," Science, vol. 297, no. 5580, pp. 353-356, 2002.

[6] C. Haass and D. J. Selkoe, "Soluble protein oligomers in neurodegeneration: lessons from the Alzheimer's amyloid $\beta$ peptide," Nature Reviews Molecular Cell Biology, vol. 8, no. 2, pp. 101-112, 2007. 
[7] T. Müller, H. E. Meyer, R. Egensperger, and K. Marcus, "The amyloid precursor protein intracellular domain (AICD) as modulator of gene expression, apoptosis, and cytoskeletal dynamics-Relevance for Alzheimer's disease," Progress in Neurobiology, vol. 85, no. 4, pp. 393-406, 2008.

[8] D. van Gool, B. de Strooper, F. van Leuven, and R. Dom, "Amyloid precursor protein accumulation in Lewy body dementia and Alzheimer's disease," Dementia, vol. 6, no. 2, pp. 63-68, 1995.

[9] M. R. Palmert, M. B. Podlisny, D. S. Witker et al., "Antisera to an amino-terminal peptide detect the amyloid protein precursor of Alzheimer's disease and recognize senile plaques," Biochemical and Biophysical Research Communications, vol. 156, no. 1, pp. 432-437, 1988.

[10] A. Nikolaev, T. McLaughlin, D. D. M. O’Leary, and M. TessierLavigne, "APP binds DR6 to trigger axon pruning and neuron death via distinct caspases," Nature, vol. 457, no. 7232, pp. 981989, 2009.

[11] A. Weidemann, G. Konig, D. Bunke et al., "Identification, biogenesis, and localization of precursors of Alzheimer's disease A4 amyloid protein," Cell, vol. 57, no. 1, pp. 115-126, 1989.

[12] J.-M. Roch, I. P. Shapiro, M. P. Sundsmo et al., "Bacterial expression, purification, and functional mapping of the amyloid B/A4 protein precursor," Journal of Biological Chemistry, vol. 267, no. 4, pp. 2214-2221, 1992.

[13] R. Bhasin, W. E. van Nostrand, T. Saitoh et al., "Expression of active secreted forms of human amyloid $\beta$-protein precursor by recombinant baculovirus-infected insect cells," Proceedings of the National Academy of Sciences of the United States of America, vol. 88, no. 22, pp. 10307-10311, 1991.

[14] J. Knops, K. Johnson-Wood, D. B. Schenk, S. Sinha, I. Lieberburg, and L. McConlogue, "Isolation of baculovirus-derived secreted and full-length $\beta$-amyloid precursor protein," Journal of Biological Chemistry, vol. 266, no. 11, pp. 7285-7290, 1991.

[15] H. Zhang, H. Komano, R. S. Fuller, S. E. Gandy, and D. E. Frail, "Proteolytic processing and secretion of human $\beta$-amyloid precursor protein in yeast. Evidence for a yeast secretase activity," Journal of Biological Chemistry, vol. 269, no. 45, pp. 27799-27802, 1994.

[16] I. Ohsawa, Y. Hirose, M. Ishiguro, Y. Imai, S. Ishiura, and S. Kohsaka, "Expression, purification, and neurotrophic activity of amyloid precursor protein-secreted forms produced by yeast," Biochemical and Biophysical Research Communications, vol. 213, no. 1, pp. 52-58, 1995.

[17] A. Henry, C. L. Masters, K. Beyreuther, and R. Cappai, "Expression of human amyloid precursor protein ectodomains in Pichia pastoris: analysis of culture conditions, purification, and characterization," Protein Expression and Purification, vol. 10, no. 2, pp. 283-291, 1997.

[18] W. E. van Nostrand, A. H. Schmaier, R. S. Siegel, S. L. Wagner, and W. C. Raschke, "Enhanced plasmin inhibition by a reactive center lysine mutant of the Kunitz-type protease inhibitor domain of the amyloid $\beta$-protein precursor," Journal of Biological Chemistry, vol. 270, no. 39, pp. 22827-22830, 1995.

[19] S. L. Wagner, R. S. Siegel, T. S. Vedvick, W. C. Raschke, and W. E. van Nostrand, "High level expression, purification, and characterization of the Kunitz-type protease inhibitor domain of protease nexin-2/amyloid $\beta$-protein precursor," Biochemical and Biophysical Research Communications, vol. 186, no. 2, pp. 1138-1145, 1992.
[20] K. de Schutter, Y.-C. Lin, P. Tiels et al., "Genome sequence of the recombinant protein production host Pichia pastoris," Nature Biotechnology, vol. 27, no. 6, pp. 561-566, 2009. 

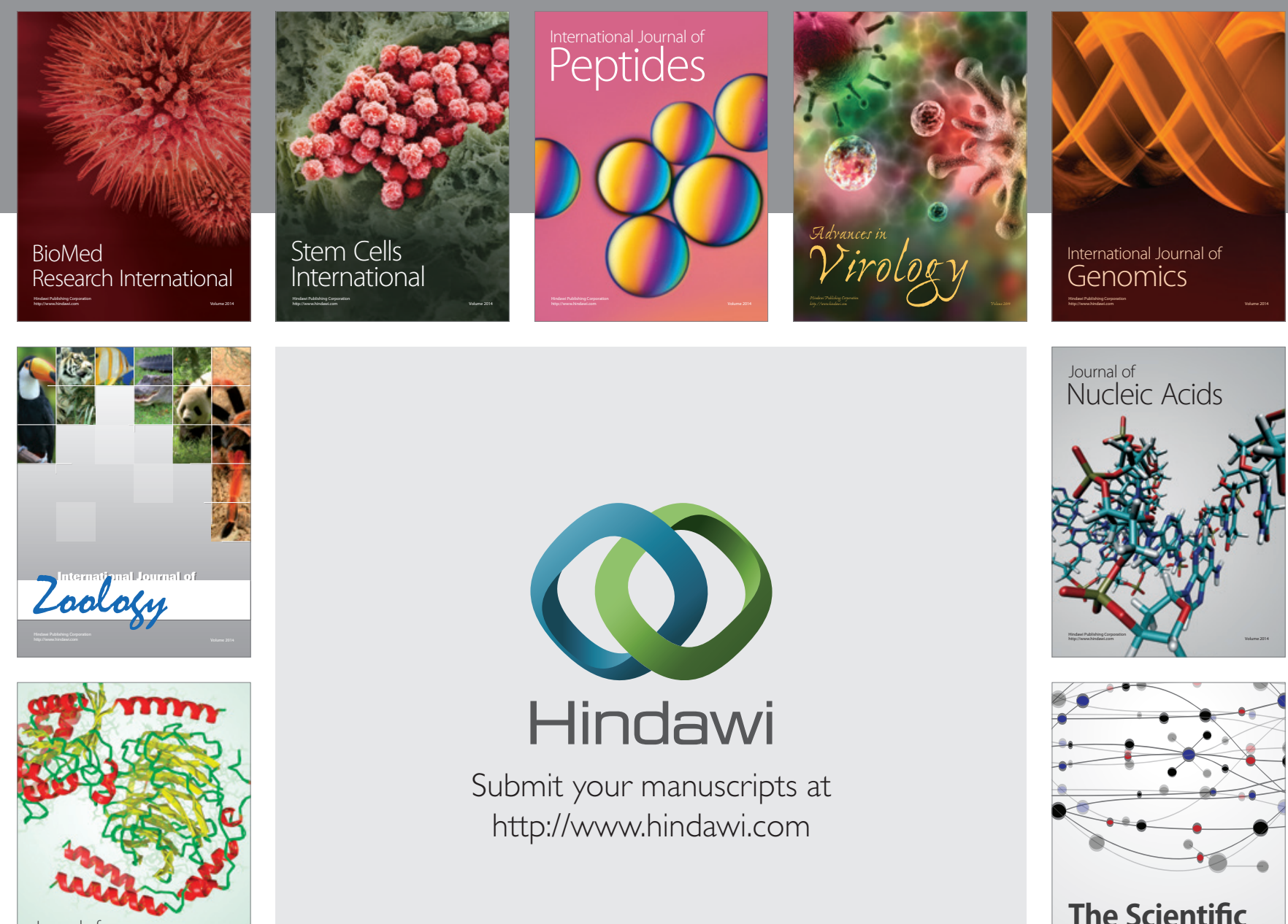

Submit your manuscripts at

http://www.hindawi.com

Journal of
Signal Transduction
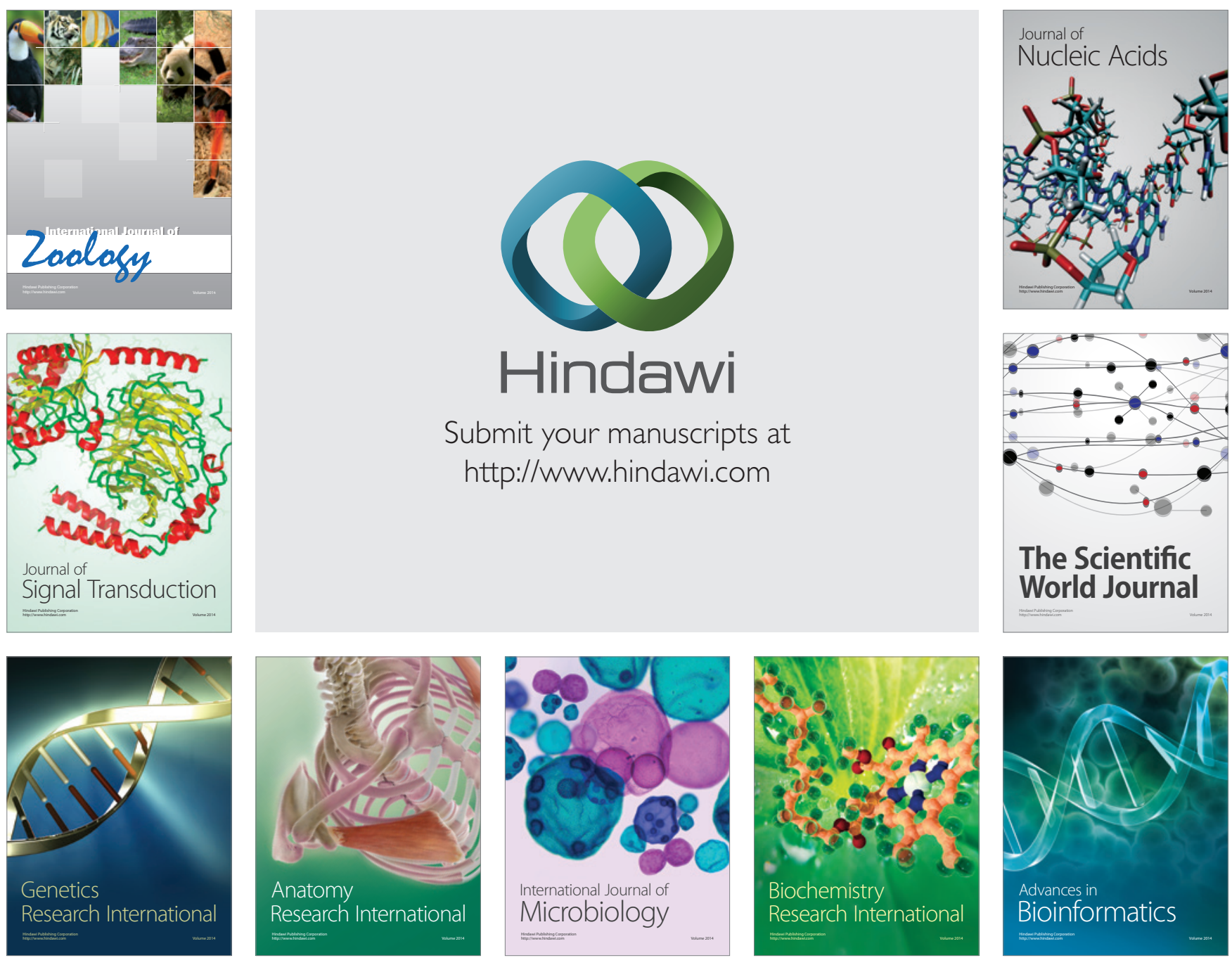

The Scientific World Journal
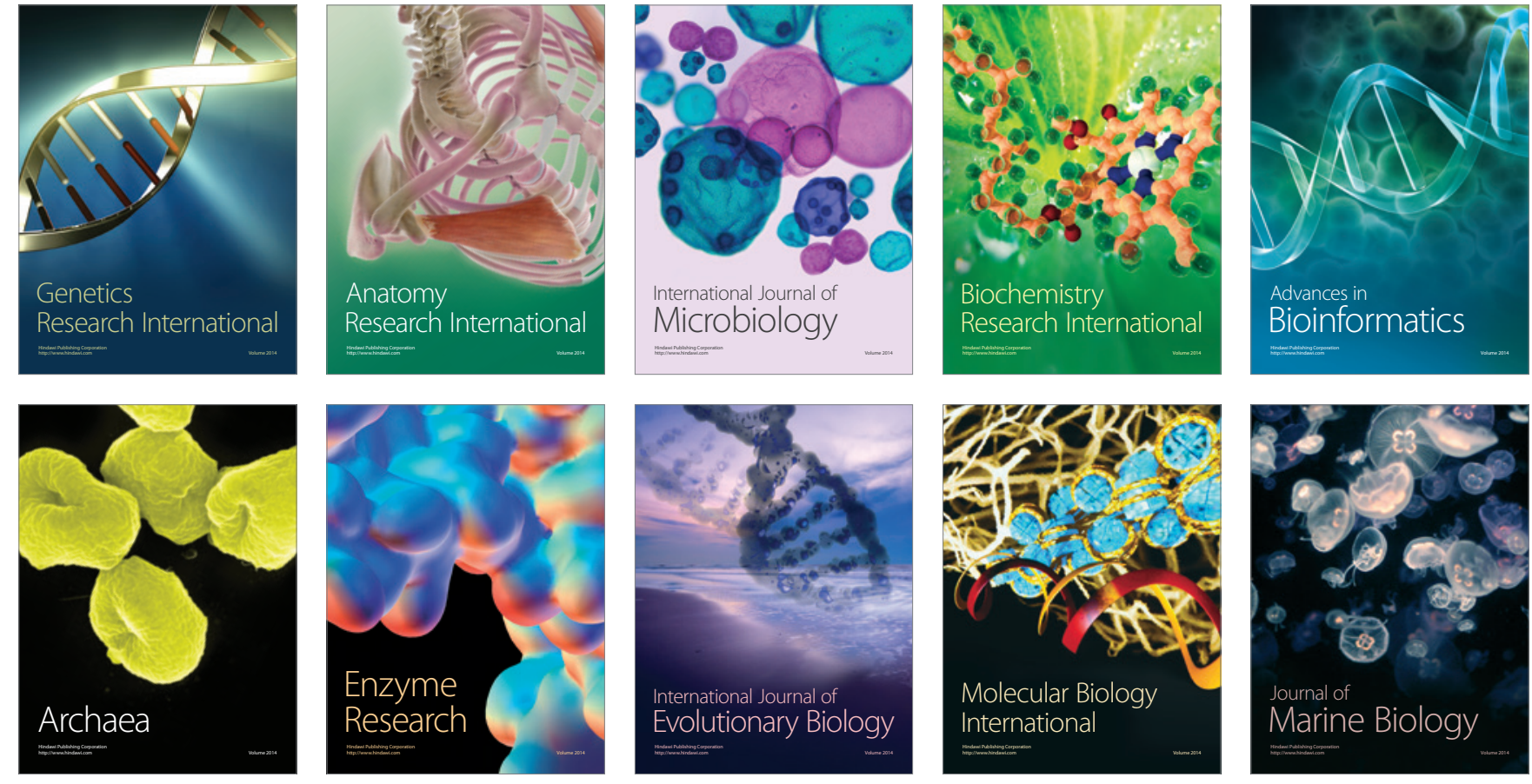